\title{
Awareness and source of AIDS-related prevention knowledge among medical university students of Guizhou province, China
}

\author{
Yanna Zhou, Wanjin Yang, Xue Wang, Haiyan Wang, Deyu Zhu, Xiuquan Shi* \\ Department of Epidemiology and Health Statistics, School of Public Health, Zunyi Medical University, Zunyi, Guizhou, China
}

Received: January 1, 2019

Accepted: March 27, 2019

Online Published: April 9, 2019

DOI: $10.5430 /$ jer.v5n2p1

URL: https://doi.org/10.5430/jer.v5n2p1

\begin{abstract}
Objectives: To clarify the awareness and source of AIDS knowledge among college students of medical university of Guizhou province, China, so as to provide some basic evidences for implementing education of AIDS control and prevention.

Methods: A stratified cluster sampling survey was conducted. Self-designed questionnaires were used to investigate university students, Epidata 3.0 and SPSS 18.0 were used to analyze data.

Results: The awareness rate of AIDS through blood transmission and mother-to-child transmission was over $90 \%$, the awareness rate of sexual transmission was just about $80 \%$, and the awareness rate of non- transmission route "mosquito bites will not spread AIDS" was only 53.3\%. The awareness rate of AIDS transmission and treatment among medical students was higher than that of non-medical students. The Internet, propaganda materials, newspapers and magazines, and school classes were the main ways for university students to acquire AIDS knowledge. Some students hope to acquire knowledge from classmates and friends, it was found that the proportion of medical students receiving AIDS knowledge from school classes was significantly higher than that of non-medical students $(80.8 \%$ vs. $73.1 \%, p=.007)$.

Conclusion: Though the awareness rate of AIDS knowledge among medical students is better than that of non-medical students, they had insufficient knowledge of AIDS, especially the sexual transmission. Moreover, school classes may be an effective way to propagandize AIDS-related knowledge, so schools can consider publicizing the AIDS education through classes, so as to improve students' abilities of AIDS control and prevention.
\end{abstract}

Key Words: Medical university students, AIDS

\section{INTRODUCTION}

Acquired Immune Deficiency Syndrome (AIDS) is a leading cause of the global burden of disease and mortality. ${ }^{[1]}$ In June 1985, China discovered the first case of HIV infection, by the end of the December 30, 2017, China has reported 758 610 living HIV infections and AIDS patients, 239289 deaths, 437377 living HIV infections and 321233 AIDS patients. ${ }^{[2]}$
Around the world, about half of all new cases of HIV occur in youth between age 15 and 24 years. ${ }^{[3]}$ In 2005 , the ministry of health listed university students as high-risk groups for HIV/AIDS. ${ }^{[4]}$ In recent years, a disproportionate increase in the incidences of new HIV infections has been noted among 15-24 year olds, when compared with other population segments in many countries including China. Statistics from the

\footnotetext{
*Correspondence: Xiuquan Shi; Email: xqshi@zmc.edu.cn; Address: Department of Epidemiology and Health Statistics, School of Public Health, Zunyi Medical University, Zunyi Guizhou 563006, P.R.China.
} 
Chinese Center for Disease Control and Prevention (China CDC) revealed that new HIV infections amongst young students increased from $0.96 \%$ of all cases in 2006 to $1.73 \%$ in 2011. ${ }^{[5]}$ University students are in a sexually active stage, and there is a potential risk of HIV/AIDS infection. ${ }^{[6]}$ As the main force of national talent training, university students accept higher education and have a higher sense of responsibility, which is also the effective force of national HIV/AIDS prevention and control and knowledge publicity. Therefore, it is of great significance to understand the awareness of knowledge of AIDS among university students and the main ways to acquire knowledge, provide theoretical basis for making AIDS prevention and control measures, and improve university students' abilities to prevent and control AIDS.

\section{OBJECTS AND METHODS}

\subsection{Objects}

University students in a medical university campus in Guizhou province, China.

\subsection{Methods}

A standardized and unified self-designed closed-end questionnaire "University students AIDS related knowledge questionnaire" was used for the survey. The contents of the questionnaire include social demographic information, including gender, age, grade, major and native place, eight AIDS-related knowledge that the public needs to master and other knowledge related to AIDS prevention and control, the approach of obtaining and hoping to obtain AIDS knowledge, and some questions about the attitude and practice, there were 25 questions in total. Cronbach's $\alpha$ was used to evaluated the reliability of the questionnaire, the value was 0.553 , and the Kaiser-Meyer-Olkin measure of sampling adequacy was used to evaluate the validity, the value was 0.759 , these indicated that the questionnaire could be accepted. Stratified cluster sampling was used to recruit 972 university students in a medical university campus in Guizhou province, China from December 2017 to March 2018 as the survey objects. Stratification was carried out according to different grades and majors.

Before the survey, the investigators accepted an unified training, then the investigators entered the classes and distributed questionnaires, after signing the informed consent, students were given sufficient time to answer the questions independently, and questionnaires were collected on the spot. A total of 972 questionnaires were distributed, 944 valid questionnaires were regained, and the valid rate was $97.1 \%$.

\subsection{Statistical analysis}

Epidata 3.0 (EpiData Association, http: //www . epidata . $\mathrm{dk} /$, Denmark) software was used for data entry and error detection, SPSS 18.0 (IBM Corp., Armonk, NY, USA) was used for statistical analysis, measurement data was described by mean $\pm \mathrm{SD}$, counting data was described by constituent ratio or rate, Chi-square test was used for comparison between groups, and the significant level $\alpha=0.05$.

\section{RESUltS}

\subsection{Social demographic information}

A total of 944 students (345 males and 599 females) aged 17-26 years were surveyed, and the average age was (21.1 \pm 1.8 ) years old. Out of the 944 respondents, there were 609 medical students and 335 non-medical students, the number of respondents from grade one to grade five were 194 (20.5\%), 237 (25.1\%), 220 (23.3\%), 170 (18.0\%), 123 $(13.1 \%)$, respectively.

\subsection{The awareness rate of AIDS knowledge}

Among the eight AIDS knowledge that the public needs to master, the awareness rate of AIDS transmitted by blood and from mother-to-child was over $90 \%$, the awareness rate of sexual contact was just about $80 \%$, and the awareness rate of non-transmission route "mosquito bites will not spread AIDS" was only $53.3 \%$. Among the other knowledge related to AIDS, over $80 \%$ respondents knew that AIDS is a serious infectious disease and may not be cured, $59.5 \%$ of the subjects knew "If AIDS patients accept effective antiviral treatment, they can survive like healthy people", only $40.0 \%$ of the respondents knew "The most famous treatments for AIDS is cocktail therapy". When compared with nonmedical students, the awareness rate of transmission routes and treatment among the medical students was higher $(P<$ $.05)$, while the difference was not found in the awareness rate of other knowledge related to AIDS, such as "Which day is the world AIDS day", "People infected with HIV can not be identified by their appearance", and "If AIDS patients accept effective antiviral treatment, they can survive like healthy people" (see Table 1).

\subsection{The routes of obtaining AIDS knowledge}

Through this survey, it was found that propaganda materials, newspapers and magazines, Internet and school classes were the main routes of obtaining AIDS knowledge of students, and over $80 \%$ students hope to acquire AIDS knowledge through propaganda materials, newspapers and magazines, Internet and school classes, while some students want to acquire from their classmates and friends (see Table 2). When compared with non-medical students, the proportion of obtaining HIV/AIDS knowledge from school classes of medical 
students was significantly higher than that of non-medical significantly lower than that of non-medical students $(p<$ students $(p<.05)$, the proportion of obtaining HIV/AIDS .05), while the difference was not found in other routes. (see knowledge from television and radio of medical students was Table 3)

Table 1. The awareness rate of AIDS knowledge among students of different majors

\begin{tabular}{|c|c|c|c|c|c|}
\hline AIDS knowledge & $\begin{array}{l}\text { Total } \\
\text { n(\%) }\end{array}$ & $\begin{array}{l}\text { Medical } \\
\text { n(\%) }\end{array}$ & $\begin{array}{l}\text { Non-medical } \\
\text { n(\%) }\end{array}$ & $\chi^{2}$ & $p$-value \\
\hline \multicolumn{6}{|l|}{ The eight AIDS knowledge that the public needs to master } \\
\hline One will get AIDS through inputting with the blood of HIV & $916(97.0)$ & $600(98.5)$ & $316(94.3)$ & 13.21 & $<.001$ \\
\hline One may get AIDS by sharing syringes & $899(95.2)$ & $588(96.6)$ & $311(92.8)$ & 6.57 & .010 \\
\hline $\begin{array}{l}\text { The pregnant woman infected with HIV may born an AIDS } \\
\text { baby. }\end{array}$ & 868 (91.9) & $586(96.2)$ & $282(84.2)$ & 42.35 & $<.001$ \\
\hline $\begin{array}{l}\text { One will not be infected with AIDS through common meals } \\
\text { with AIDS patients or HIV infected patients }\end{array}$ & $803(85.1)$ & $545(89.5)$ & $258(77.0)$ & 26.48 & $<.001$ \\
\hline $\begin{array}{l}\text { People infected with HIV can not be identified by their } \\
\text { appearance }\end{array}$ & $789(83.6)$ & $518(85.1)$ & $271(80.9)$ & 2.73 & .099 \\
\hline The correct use of condoms can reduce the spread of AIDS & $782(82.8)$ & $530(87.0)$ & $252(75.2)$ & 21.19 & $<.001$ \\
\hline $\begin{array}{l}\text { Only to have sexual relations with a sexual partner can reduce } \\
\text { the spread of AIDS }\end{array}$ & 726 (76.9) & $500(82.1)$ & $226(67.5)$ & 26.08 & $<.001$ \\
\hline Mosquito bites will not spread AIDS & $503(53.3)$ & $350(57.5)$ & $153(45.7)$ & 12.09 & .001 \\
\hline \multicolumn{6}{|l|}{ Other knowledge related to AIDS } \\
\hline AIDS is a serious infectious disease & $817(86.5)$ & $541(88.8)$ & $276(82.4)$ & 7.71 & .005 \\
\hline AIDS can not be cured & $805(85.3)$ & $547(89.8)$ & $258(77.0)$ & 28.22 & $<.001$ \\
\hline Which day is the world AIDS day & $761(80.6)$ & $488(80.1)$ & $273(81.5)$ & 0.26 & .613 \\
\hline There is no effective vaccine for preventing HIV/AIDS & $678(71.8)$ & $486(79.8)$ & $192(57.3)$ & 54.01 & $<.001$ \\
\hline $\begin{array}{l}\text { If AIDS patients accept effective antiviral treatment, they can } \\
\text { survive like healthy people }\end{array}$ & $562(59.5)$ & $371(60.9)$ & $191(57.0)$ & 1.37 & .242 \\
\hline The most famous treatments for AIDS is cocktail therapy & $378(40.0)$ & $312(51.2)$ & 66 (19.7) & 89.49 & $<.001$ \\
\hline
\end{tabular}

Table 2. The main and hope routes of obtaining AIDS knowledge $(n=944)$

\begin{tabular}{|c|c|c|c|c|c|}
\hline Routes & $\begin{array}{l}\text { Main } \\
\text { routes(\%) }\end{array}$ & $\begin{array}{l}\text { Expectancy } \\
\text { routes(\%) }\end{array}$ & Routes & $\begin{array}{l}\text { Main } \\
\text { routes(\%) }\end{array}$ & $\begin{array}{l}\text { Expectancy } \\
\text { routes(\%) }\end{array}$ \\
\hline School classes & 737 (78.1) & 768 (81.4) & Propaganda film & $536(56.8)$ & $693(73.4)$ \\
\hline Television and radio & 665 (70.4) & $722(76.5)$ & $\begin{array}{l}\text { Classmates and } \\
\text { friends }\end{array}$ & $402(42.6)$ & 489 (51.8) \\
\hline $\begin{array}{l}\text { Propaganda materials, newspapers } \\
\text { and magazines }\end{array}$ & 794 (84.1) & 769 (81.5) & $\begin{array}{l}\text { Families and } \\
\text { relatives }\end{array}$ & $238(25.2)$ & 356 (37.7) \\
\hline Internet & 789 (83.6) & 780 (82.6) & Other routes & 252 (26.7) & $340(36.0)$ \\
\hline
\end{tabular}

Table 3. The comparison of the main routes of access to HIV/AIDS knowledge of students of different majors

\begin{tabular}{lllll}
\hline $\begin{array}{l}\text { Main } \\
\text { acquiring } \\
\text { routes }\end{array}$ & $\begin{array}{l}\text { Medical } \\
\mathbf{n ( \% )}\end{array}$ & $\begin{array}{l}\text { Non-medical } \\
\mathbf{n}(\%)\end{array}$ & $\chi^{\mathbf{2}}$ & $\boldsymbol{P}$-value \\
\hline School classes & $492(80.8)$ & $245(73.1)$ & 7.395 & .007 \\
$\begin{array}{l}\text { Television and } \\
\text { radio }\end{array}$ & $400(65.7)$ & $265(79.1)$ & 18.703 & $<.001$ \\
\hline
\end{tabular}

Published by Sciedu Press

\section{Discussion}

Since AIDS has spread rapidly around the world, and it continues to be a major global public health problem, and prevention is the main strategy to deal with the AIDS pandemic. ${ }^{[7]}$ Therefore, it is urge to improve people's abilities to prevent and control AIDS by popularize knowledge of AIDS prevention. University students are in a sexually active stage, and there is a potential risk of HIV/AIDS infection. ${ }^{[6]}$ Studies have shown that the main transmission route of HIV/AIDS 
changes from injecting drug to sexual transmission, and the number of young students with HIV/AIDS increases year by year. ${ }^{[8]}$ In this survey, our results indicated that the AIDS publicity and education work in universities has made some progress, while the students still had insufficient knowledge of AIDS prevention, the same as the result of Asad Ali and colleagues, ${ }^{[9]}$ especially how to avoid the sexual transmission, for the reason that the awareness rate of knowing "Only to have sexual relations with a sexual partner can reduce the spread of AIDS" was only $76.9 \%$. As sexual transmission is the main transmission route in Guizhou province, China, ${ }^{[10]}$ therefore, the AIDS publicity and education in universities should be strengthened to improve their abilities to prevent and control AIDS.

About the transmission methods and treatments of AIDS, the awareness of medical students was significantly higher than that of non-medical students, the result is consistent with that of Liu and colleagues. ${ }^{[11]}$ This result was attributed to the fact that medical students had learned more AIDS-related knowledge in classes and internship. At the same time, it also reminds us that the effect of acquiring AIDS knowledge in the classroom cannot be ignored and school classes may be an effective way to spread knowledge of AIDS prevention, so class meetings and lectures could be used to publicize AIDS knowledge.

In addition, it was found that propaganda materials, newspapers and magazines, the Internet and school classes were the main routes of obtaining HIV/AIDS knowledge, the same to the expected routes. While some other expected ways to acquire knowledge from classmates and friends, which are also necessary, so it suggests that we can add peer ed-

\section{REFERENCES}

[1] Qu D, Zhong XN, Xiao GY, et al. Adherence to pre-exposure prophylaxis among men who have sex with men: A prospective cohort study. International Journal of Infectious Diseases. 2018, 75; 52-59. PMid:30125688. https://doi.org/10.1016/j.ijid.2018.08 .006

[2] Chinese center for disease control and prevention, National center for AIDS/STD control and prevention, In December 2017, the national AIDS disease outbreaks. Chinese journal of AIDS and STD. 2018; 24(2): 111 .

[3] Menna T, Ali A, Worku A. Effects of peer education intervention on HIV/AIDS related sexual behaviors of secondary school students in Addis Ababa, Ethiopia: a quasi-experimental study Reproductive Health. 2015; 12(1): 84. PMid:26346980. https: //doi.org/10.1186/s12978-015-0077-9

[4] Zhang YP. Investigation and evaluation on AIDS knowledge, attitude and practice of students in a university of Shenyang City, Liaon- ucation to publicize knowledge of AIDS. ${ }^{[12]}$ Moreover, the proportion of obtaining HIV/AIDS knowledge from school classes of medical students was significantly higher than that of non-medical students, and the awareness rate of AIDS knowledge was significantly higher than those students other than medical major, besides, the results of Martin Kuete and colleagues indicated that the students whose source of information was mainly from school education were more knowledgeable compared with the students whose source of information was more likely to use Internet, ${ }^{[13]}$ both the two results confirmed the effect of school classes used in spread knowledge of AIDS prevention.

\section{Conclusion}

The students had incomplete knowledge of AIDS, especially the sexual transmission, the awareness of AIDS knowledge among medical students is better than that of non-medical students, and school classes may be an effective way to propagandize knowledge of AIDS prevention. Schools can consider publicizing the knowledge of AIDS through classes, so as to improve students' abilities to prevent and control AIDS.

\section{ACKNOWLEDGEMENTS}

This study was granted by special funding for the discipline construction of doctoral degree authorization of Zunyi Medical University (Grant No. 2015-996036; PI: Xiuquan Shi). The funder had no role in study design, data collection and analysis, decision to publish, or preparation of the manuscript.

\section{CONFlicts of InTEREST Disclosure}

The authors declare no conflict of interest ing Province. Chinese Journal of Health Education. 2011; 27(8): 596-599.

[5] Chen M, Liao Y, Liu J, et al. Comparison of Sexual Knowledge, Attitude, and Behavior between Female Chinese College Students from Urban Areas and Rural Areas: A Hidden Challenge for HIV/AIDS Control in China. BioMed Research International. 2016; 2016: 10. PMid:28101513. https://doi.org/10.1155/2016/8175921

[6] Dai MB. The evaluation of health education intervention of AIDS knowledge attitude behavior among college freshmen. Chinese Journal of Public Health. 2013; 29(4): 606-607.

[7] Ehsan Z, Roghayeh K, Maryam T, et al. Knowledge of and attitudes toward HIV/AIDS among Iranian women. Epidemiology and Health. 2018; 40: 1-7. PMid:30081620. https://doi .org/10.4178/ep ih.e2018037

[8] Wu ZY. The prevention and control situation and strategy of school in our country. Chinese Journal of School Health. 2015; 36(11): 1604-1605. 
[9] Ali A, Ali NS, Nasir U, et al. Comparison of Knowledge and Attitudes of Medical and Dental Students towards HIV/AIDS in Pakistan. Cureus, 2018.https : //doi .org/10.7759/cureus . 2426

[10] Yuan Z, Cao WJ, Yao YM, et al. Epidemic trend and characteristics of AIDS in Guizhou, 2011-2015. Modern Preventive Medicine. 2017; 44(15): 2707- 2711

[11] Liu F, Qi BN, Zhang Y, et al. Analysis on the Awareness Rate of AIDS Knowledge and Its inFluencing Factors in a Medical College in Shanxi. Chinese Journal of Dermatovenereology. 2017; 31(7): 792-794.
[12] Timol F, Vawda MY, Bhana A, et al. Addressing adolescents' risk and protective factors related to risky behaviours: Findings from a school-based peer-education evaluation in the Western Cape. Sahara Journal of Social Aspects of HIV/AIDS Research Alliance. 2016; 13(1): 197-207. PMid:27892820. https://doi .org/10.1080/17 290376.2016.1241188

[13] Martin K, Qiao H, Abid R, et al. Differences in Knowledge, Attitude, and Behavior towards HIV/AIDS and Sexually Transmitted Infections between Sexually Active Foreign and Chinese Medical Students. BioMed Research International. 2016; 2016: 10. 